\section{Individual placement and support programme increases rates of obtaining employment in people with severe mental illness}

\section{QUESTION}

Question: Is an individual placement and support (IPS) programme effective for helping people with severe mental health disorders gain open employment in Europe?

Patients: 312 adults (aged between 18 years and local retirement age) with psychotic illness or bipolar disorder, validated by structured assessment of case notes. Inclusions: community dwelling, major role dysfunction for $\geqslant 2$ years, had not been in competitive employment for the past year but wished to do so.

Setting: UK, Germany, Italy, Switzerland, Bulgaria and the Netherlands; April 2003 to November 2005.

Intervention: Individual placement and support (IPS)-a supported employment intervention, or standard rehabilitation and vocational services. IPS involved a worker with an established network of employees willing to accept people with mental health problems, helping participants to develop realistic goals and seek appropriate employment. Vocational service was the main alternative rehabilitation service available in the area. It involved assessment of patient needs, and a structured training programme of work skills offered throughout the week (for example, time management, routine attendance at the centre, and IT skills). Interviews were carried out at baseline, 6, 12 and 18 months.

Outcomes: Proportion of people entering competitive employment and working for at least one day. Secondary outcomes: duration of employment (hours and days employed), job tenure, dropout from service, and admission to hospital. Factors that may explain heterogeneity of effectiveness of IPS between centres, due to the effect of the labour market, were considered in prospective meta-analysis, and included local unemployment rate, long-term national unemployment, change in gross domestic product, benefit trap, and indirect income redistribution.

Patient follow-up: $81 \%$ at 18 month follow-up.

\section{METHODS}

Design: Randomised controlled trial.

Allocation: Concealed.

Blinding: Unblinded.

Follow-up period: 18 months.

\section{MAIN RESULTS}

IPS was more effective than vocational service across all centres for placing more people in employment for at least one day during the follow-up period (percentage of people: $55 \%$ with IPS vs $28 \%$ with vocational service; difference $26.9 \%, 95 \%$ CI $16.4 \%$ to $37.4 \%$ ). IPS also increased number of hours worked (difference in hours: $308.7,95 \%$ CI 189 to 434), and number of days employed (difference in days: $99.8,95 \%$ CI 71 to 129). Service dropout was higher with vocational services than IPS (percentage difference in hospital admission rates: 32.1 , 95\% CI 22.7 to 41.5 ) as was hospital admission (percentage difference in hospital admission rates: 11.2, 95\% CI 0.90 to 21.5). Effectiveness of IPS was significantly affected by local unemployment $(p=0.016)$. Effectiveness of either service was significantly affected by long-term unemployment $(p<0.001)$, increase in GDP $(p=0.002)$, and benefit trap $(p=0.004)$.

\section{CONCLUSIONS}

Individual placement and support increases the employment outcomes for people with severe mental illness. IPS is effective in countries with different welfare and labour markets; however this effectiveness is likely to be greater in countries that have a growing economy and job creation.

\section{ABSTRACTED FROM}

Burns T, Catty J, Becker $\mathrm{T}$, et al. The effectiveness of supported employment for people with severe mental illness: a randomised controlled trial. Lancet 2007;370:1146-52.

Notes: Analyses did not use intention to treat and data were not available for some of the outcomes.

Correspondence to: Professor T Burns, University Department of Psychiatry, Warneford Hospital, Oxford OX3 7JX, UK; Tom.Burns@psych.ox.ac.uk

Source of funding: European Union Quality of Life and Management of Living Resources Programme.

- An additional reference list is published online only at http://ebmh.bmj.com/content/ vol11/issue2 urveys suggest that the majority of adults with

$S$ severe mental illness would like to work preferably in non-sheltered, competitive settings. Such work is widely considered an important ingredient in recovery. ${ }^{1}$ Rates of employment among people with severe mental illness, however, are typically low. Randomised trials of supported employment in the USA and more recently also in Canada, Hong Kong and Australia, ${ }^{2}$ especially when it conforms to the individual placement and support (IPS) model, have consistently yielded better competitive employment outcomes than alternative approaches. This is the first randomised trial of IPS in Europe.

Fidelity ratings achieved at the six sites, indicating fair to good implementation of IPS, combined with the employment outcomes, suggest that this type of programme can be successfully implemented in diverse European countries. Taken with other evidence from the USA, this suggests that clinicians in Europe should refer any client who desires to work in a competitive setting to a well-functioning IPS programme - if one is available.

The prospect of large-scale implementation of IPS in Europe, however, raises several questions. Given evidence of an association between higher model fidelity and better employment outcomes, what can be done to ensure consistently high-fidelity implementation? In particular, how can lessons learned in the USA concerning successful implementation of IPS programmes best be transposed to European settings? ${ }^{3}$ Also, what programme capacity is it cost-effective to provide in a service system? And, finally, if greater disincentives to work impede entry into the competitive workforce, as this study's pathbreaking findings concerning the effects of a "benefits trap" suggest, how can values of social solidarity, fairness and providing real incentives to work best be reconciled? Further research is needed to clarify how best to implement this revolutionary approach to vocational rehabilitation.

\section{Eric A Latimer, PhD}

Douglas Mental Health University Institute and Department of Psychiatry, McGill University, Montreal, Canada

Competing interests: None. 